\title{
O CONTEXTO HISTÓRICO SOCIAL E OS CENÁRIOS DO CUIDADO EM SAÚDE MENTAL NA ATUALIDADE
}

\section{Margarita Antonia Villar Luis}

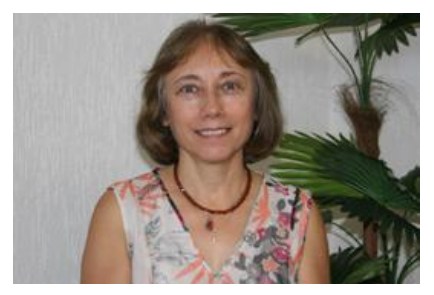

\begin{abstract}
Este foi o tema do XI Encontro de Pesquisadores
\end{abstract} em Saúde Mental e Especialistas em Enfermagem Psiquiátrica, ocorrido em junho de 2010, em Ribeirão Preto, realizado pelo Departamento de Enfermagem Psiquiátrica e Ciências Humanas da Escola de Enfermagem de Ribeirão Preto/USP e apoiado por órgãos financeiros governamentais - CNPq e Capes.

A categoria saúde mental engloba várias possibilidades, distintas análises e perspectivas que vão compor uma área de conhecimento que se dedica à busca teórica das origens da doença e sofrimento psíquico e/ou às formas de intervenção, com ações práticas voltadas a minimizar suas manifestações.

Embora termos que denotam doença, como transtorno ou distúrbios, estejam consolidados entre alguns segmentos de profissionais da área da saúde mental, outros preferem utilizar o termo sofrimento psíquico para nominar manifestações que denotam comprometimento da função cerebral. Para esses, o sofrimento psíquico compreende diferentes graus de alteração neurológica, psicológica e motora, bem como, também, compreende quadros psicopatológicos, manifestados através de surtos agudos ou episódios mais brandos, mas todos igualmente penosos para os portadores que vivenciam essas experiências humanas.

Nos últimos tempos, as situações incorporadas ao âmbito da saúde mental têm aumentado, pois o viver em sociedade vem se traduzindo no manejo de vivências mais complexas pelo enfrentamento de constantes mudanças e eventos hostis, para os quais as pessoas, na maior parte das vezes, não estão preparadas.

Seguindo essa perspectiva, o tema do evento se propôs a trazer para discussão diversas condições danosas, 
decorrentes de fatores de ordem biológica (anatômica/fisiológica), de ordem somatogênica, daquelas provenientes do próprio meio interno do indivíduo, tais como representações e afetos que caracterizam seus comportamentos peculiares e, também, as agressões originárias no espaço social onde transita.

Considerando a importância do resgate do papel profissional do enfermeiro na atenção à saúde mental, foi dado destaque à sua atuação na assistência aos doentes assim como à produção do conhecimento específico, sob perspectiva histórico-crítica.

O contexto de vida, os espaços de convívio e locomoção das pessoas remeteram ao binômio violência e saúde mental e às experiências geradoras de estresse e crises existenciais, assim como às estratégias de enfrentamento utilizadas pelas pessoas.

No presente momento, o cuidado prestado ao enfermo mental, no Centro de Atenção Psicossocial, serviços de saúde, definidos pelas diretrizes políticas de saúde brasileiras, como protagonistas no cenário da atenção à saúde mental, está sendo alvo de questionamentos. Da mesma forma, esses locais estão em processo de avaliação, visando comprovar sua eficácia e identificar potencialidades e fraquezas. Esse diagnóstico é especialmente importante para garantir a sobrevivência do paradigma teórico prático da reforma psiquiátrica, inspirador dessa modalidade de serviços que, indiscutivelmente, trouxe benefícios ao enfermo mental.

Razão pela qual o conhecimento de como vem ocorrendo o processo de reabilitação e reinserção social do doente mental, em outros países, constitui oportunidade para agregar experiências e informações ao saber teórico e prático, possuído pelos profissionais do Brasil, atuantes na área.

Esses assuntos fizeram parte da programação do evento referido, no qual houve a presença de 299 inscritos, sendo 82\% procedentes da Região Sudeste, 6,0\% da Região Sul, 5,4\% da Região Centro-Oeste, 4,5\% das Regiões Norte e Nordeste e 2,0\% de outros países. Destacaram-se, numericamente, (excluindo o Estado de São Paulo), em termos de participação, os Estados do Rio de Janeiro, Minas Gerais, Espírito Santo, Paraná e Goiás, respectivamente. 
Na área da saúde, 45,5\% eram da enfermagem (4 eram auxiliares de enfermagem) e $11 \%$ distribuíram-se entre os demais profissionais, com destaque para os psicólogos. Em outras áreas, houve a participação de 5 pessoas $(1,6 \%)$ e, na categoria alunos, 34,5\% foram discentes de cursos de graduação e 7\% da pós-graduação de vários cursos da saúde.

Cabe destacar, ainda, que foram submetidos 318 trabalhos, 29 dos quais na íntegra para concorrer ao prêmio Professora Doutora Maria Aparecida Minzoni, e, no total, foram aprovados 309 trabalhos para apresentação oral e em pôster e selecionados três para receberem o prêmio mencionado e menções honrosas.

Este volume especial inclui parte da experiência que foi esse evento, ao conter algumas das conferências proferidas nas mesas redondas e os trabalhos premiados. A expectativa é de que os leitores utilizem os artigos como fonte de estudo, reflexão e inspiração para desenvolver pesquisas, material didático ou, ainda, incentivar discussões entre alunos e colegas de trabalho.

A SMAD é uma revista nova que vem se consolidando no espaço nacional e também em outros países, especialmente da América Latina. É muito importante a participação dos leitores, utilizando-a como veículo de disseminação de conhecimento e, também, como referência bibliográfica. Informem se está atendendo suas expectativas. Escrevam dando suas sugestões.

Boa leitura.

Margarita Antonia Villar Luis é editora da SMAD, Revista Eletrônica Saúde Mental Álcool e Drogas e Professor Titular da Escola de Enfermagem de Ribeirão Preto, Universidade de São Paulo, Centro Colaborador da OMS para o desenvolvimento da pesquisa em enfermagem, Brasil, e-mail: margarit@eerp.usp.br.

\section{Como citar este artigo:}

Luis MAV. O contexto histórico social e os cenários do cuidado em saúde mental na atualidade. SMAD, Rev. Eletrônica Saúde Mental Álcool Drog. (Ed. port.) [Internet]. 2010 [acesso: dia mês abreviado com ponto ano]; 6(Especial): 365-7. Disponível em: Endereço Eletrônico Visitado. 